\title{
The conceptualization and development of a patient-reported neurogenic bladder symptom score
}

This article was published in the following Dove Press journal:

Research and Reports in Urology

9 October 2013

Number of times this article has been viewed

\author{
Blayne Welk' \\ Sarah A Morrow ${ }^{2}$ \\ Wendy Madarasz ${ }^{3}$ \\ Patrick Potter ${ }^{4}$ \\ Keith Sequeira ${ }^{4}$ \\ 'Department of Surgery, Division \\ of Urology, ${ }^{2}$ Department of Clinical \\ Neurosciences, Western University, \\ London, ON, Canada; ${ }^{3}$ St Joseph's \\ Health Care, London, Ontario, \\ Canada; ${ }^{4}$ Department of Physical \\ Medicine and Rehabilitation, Western \\ University, London, ON, Canada
}

Correspondence: Blayne Welk Department of Surgery, Division of Urology, Western University, Room B4-667, St Joseph's Health Care, 268 Grosvenor Street, London, ON N6A 4V2, Canada

Tel + I 5196466367

Fax +I 5196466037

Email bkwelk@gmail.com
Background: There is no single patient-reported instrument that was developed specifically to assess symptoms and bladder-related consequences for neurogenic bladder dysfunction. The purpose of this study was to identify and consolidate items for a novel measurement tool for this population.

Methods: Item generation was based on a literature review of existing instruments, open-ended semistructured interviews with patients, and expert opinion. Judgment-based item reduction was performed by a multidisciplinary expert group. The proposed questionnaire was sent to external experts for review.

Results: Eight neurogenic quality of life measures and 29 urinary symptom-specific instruments were identified. From these, 266 relevant items were extracted and used in the creation of the new neurogenic symptom score. Qualitative interviews with 16 adult patients with neurogenic bladder dysfunction as a result of spinal cord injury, multiple sclerosis, or spina bifida were completed. Dominant themes included urinary incontinence, urinary tract infections, urgency, and bladder spasms. Using the literature review and interview data, 25 proposed items were reviewed by 12 external experts, and the questions evaluated based on importance on a scale of 1 (not important) to 5 (very important). Retained question domains had high mean importance ratings of 3.1 to 4.3 and good agreement with answer hierarchy.

Conclusion: The proposed neurogenic bladder symptom score is a novel patient-reported outcome measure. Further work is underway to perform a data-based item reduction and to assess the validity and reliability of this instrument.

Keywords: urinary bladder, neurogenic, questionnaires, quality of life, outcome assessment, health status indicators, lower urinary tract symptoms

\section{Introduction}

Neurogenic bladder dysfunction can occur with any disease or lesion that affects the nervous system, such as spinal cord injuries (SCI), multiple sclerosis (MS), or spina bifida (SB). ${ }^{1}$ Complications associated with neurogenic bladder dysfunction can cause significant morbidity and potential mortality, and the symptoms of neurogenic bladder dysfunction have been associated with a poor quality of life (QOL) among $\mathrm{SCI},{ }^{2} \mathrm{MS},{ }^{3}$ and $\mathrm{SB}^{4}$ patients.

The level and completeness of the SCI dictate the occurrence of detrusor sphincter dyssynergia and neurogenic detrusor overactivity. ${ }^{5}$ About $75 \%$ of patients with MS are estimated to have neurogenic bladder dysfunction ${ }^{6}$ with symptoms such as incontinence $(50 \%)$, retention $(25 \%)$, and overactive bladder symptoms. ${ }^{7} \mathrm{SB}$ patients often have lifelong, complex neurogenic bladder issues that may require 
surgical reconstruction. ${ }^{1}$ The urologic assessment of these patients is complex. There are multiple symptoms (such as urinary incontinence, frequency, urgency, and obstruction) and complications (such as urinary tract infections, urinary stone disease, and renal dysfunction) that may be present, and patients may be managed with a variety of medications, devices (such as intermittent or indwelling catheters), and surgical procedures.

There is currently no patient-reported outcome measure (PROM) available to quantify the relevant urinary symptoms and complications in this population. For example, many studies evaluating intravesical onabotulinum toxin among patients with neurogenic detrusor overactivity have used PROMs created to measure urinary incontinence in the general population ${ }^{8}$ rather than an instrument designed specifically for neurogenic bladder patients. A measurement tool for bladder-related QOL among patients with neurogenic bladder dysfunction has been developed; ${ }^{9}$ however, health related QOL focuses on the psychosocial and functional impacts of a condition rather than on the more objective and quantifiable clinical symptoms and consequences of a condition.

Our objective is to develop a patient-reported neurogenic bladder symptom score (NBSS). The NBSS is based on the theory that there is a set of related neurogenic bladder specific symptoms and clinical consequences common to adult SCI, MS, and SB patients (Table 1); our goal is to create a measurement tool that will be able to discriminate among patients with different levels of bladder symptoms and that it will be evaluative (responsive to change after an intervention).

Table I NBSS concepts, dimensions, and components

\begin{tabular}{|c|c|c|}
\hline Concept & Dimensions & Components \\
\hline \multirow[t]{2}{*}{$\begin{array}{l}\text { Urinary symptoms } \\
\text { and signs }\end{array}$} & Urinary storage & $\begin{array}{l}\text { Incontinence } \\
\text { Urgency/spasms } \\
\text { Frequency } \\
\text { Nocturia }\end{array}$ \\
\hline & Urinary voiding & $\begin{array}{l}\text { Weak stream } \\
\text { Pain/discomfort } \\
\text { Incomplete emptying } \\
\text { Catheter use }\end{array}$ \\
\hline \multirow[t]{2}{*}{$\begin{array}{l}\text { Urinary complications } \\
\text { and consequences }\end{array}$} & $\begin{array}{l}\text { Urinary infections } \\
\text { Stone disease } \\
\text { Renal dysfunction }\end{array}$ & $\begin{array}{l}\text { Urinary infections } \\
\text { Renal and bladder stones } \\
\text { Renal failure or } \\
\text { abnormal anatomy }\end{array}$ \\
\hline & Bladder medication & $\begin{array}{l}\text { Side effects, } \\
\text { effectiveness }\end{array}$ \\
\hline Bladder related $\mathrm{QOL}$ & $\begin{array}{l}\text { Health related } \\
\mathrm{QOL}\end{array}$ & $\begin{array}{l}\text { Bladder related distress, } \\
\text { limitations }\end{array}$ \\
\hline
\end{tabular}

Abbreviations: NBSS, neurogenic bladder symptom score; QOL, quality of life.

\section{Materials and methods}

The development of a new measurement tool consists of three stages: item generation, item reduction (using both judgment and data-based methods), and reliability and validity testing (Figure 1). ${ }^{10}$ This study describes the results of the item generation and judgment-based item reduction using the following sequential steps.

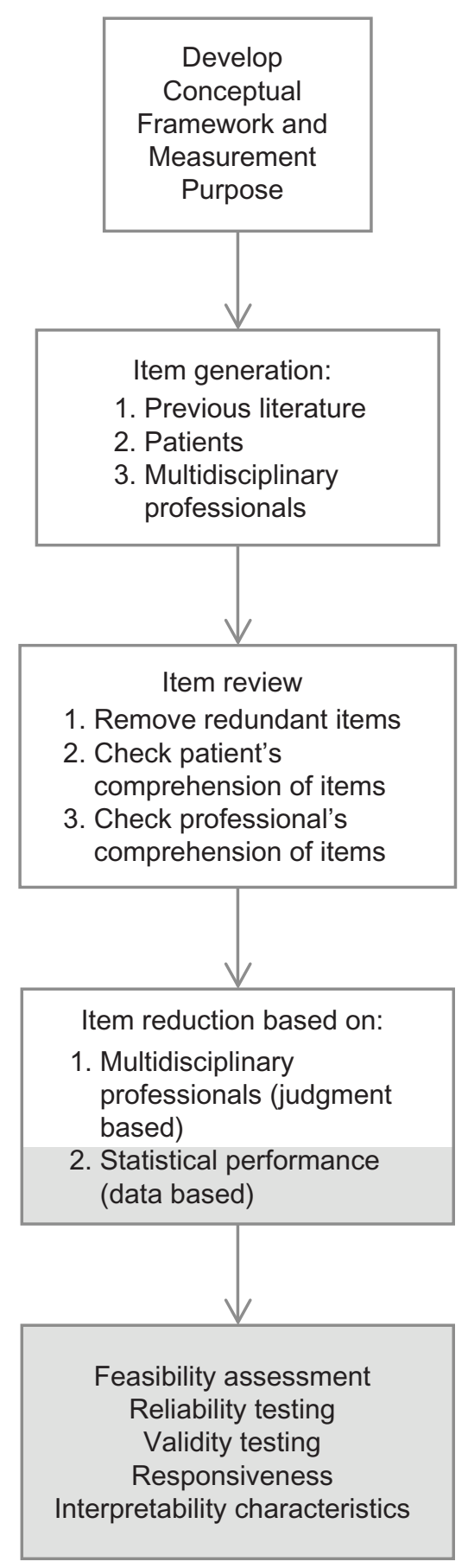

Figure I Steps in the development of a new patient-reported outcome measure. Notes: Unshaded text are steps that have been completed and are detailed within this manuscript. Shaded sections are future steps. 


\section{Literature review}

A review of the English literature was performed using Medline, ProQuest, PsychINFO, and Scopus databases. All English language, general QOL measures for SCI, MS, and SB were retrieved using a series of Medical Subject Heading (MeSH) terms and keywords ("quality of life", "questionnaires", "spinal dysraphism”, "spinal cord injuries", "multiple sclerosis"). Previous questionnaires developed for the assessment of urinary symptoms were also identified using MeSH terms and keywords ("urinary incontinence", "prostate hyperplasia", "urination", "questionnaires", "quality of life"). Only questionnaires with a formal development process (consisting of a study reporting reliability and validity) were included. The references of identified studies were reviewed to identify additional questionnaires. Relevant questions and responses were extracted and categorized using NVivo 10 (QRS International, Doncaster, VIC, Australia). NVivo software facilitates the qualitative review of patient interview content and surveys based on common themes and words.

\section{Patient interviews}

The symptoms and consequences of neurogenic bladder dysfunction were further explored using qualitative, semistructured interviews conducted among patients with SCI, MS, or SB. We utilized a standardized, open-ended questioning technique,${ }^{10}$ with questions relating to bladder symptoms as well as specific probes into known symptoms and complications. Sample size was based on data redundancy (the point at which no new concepts were being generated). Responses were transcribed, and thematic analysis was conducted by two of the authors independently using the NVivo software to code relevant themes and keywords.

\section{Expert opinion}

A multidisciplinary expert working group consisting of a urologist (with specialization in neurogenic bladder dysfunction), a neurologist (with specialization in MS), and physical medicine and rehabilitation physicians (with specialization in SCI), was assembled. Symptoms and complications of neurogenic bladder dysfunction were reviewed, and a comprehensive potential item list was generated based on data from the literature review and patient interviews. This proposed list of items was sent to multidisciplinary content experts across Canada for feedback and assessment of content validity. ${ }^{11}$ Experts were asked to rate the importance of the proposed questions in relation to neurogenic bladder (on a scale of 1 [not important] to 5 [very important]), their agreement with the hierarchy of the answers (on a scale of 1 [no hierarchy] to 5 [good hierarchy]), and asked to add any additional relevant comments. The prespecified criteria for item-retention was a mean importance rating, and a mean agreement with hierarchy greater than 3 .

\section{Patient pretesting}

The 25 revised questions were pretested on five patients with a SCI or MS to evaluate their interpretation, readability, and clarity as well as the completeness of the response choices. Questions were checked with the Question Understanding Aid $^{12}$ to identify possible correctable problems.

\section{Results}

Our literature review did not identify any existing instruments that were developed to measure neurogenic bladder symptoms. Measurement instruments found in the literature were classified as neurogenic disease specific QOL scales (eg, a SCI-specific QOL scale), or symptom-specific scales (eg, an overactive bladder symptom scale).

A total of nine neurogenic disease-specific (MS, SCI, or SB) QOL measures were identified, which had items about neurogenic bladder dysfunction (Table 2). Specific questions related to urinary function were limited to the impact of urinating on social, physical, and emotional domains as well as specific symptoms, such as urinary incontinence, frequency, and urgency. A publication addressing the qualitative development of a SCI-specific QOL instrument confirmed that bladder issues were a common problem within the physical medicine domain. ${ }^{13}$ The Qualiveen ${ }^{9}$ is a urinary specific QOL measure with domains of limitations, constraints, fears, and feelings; these domains contain a mix of physical, social, and emotional issues related to bladder dysfunction. The SCI-Secondary Complications Scale ${ }^{14}$ included two relevant questions about the prevalence of "bladder dysfunction" and urinary infections over a 3-month time course. The International SCI Data set for Lower Urinary Tract Function is not a PROM; however, it does include important standardized demographic and bladder management questions. ${ }^{15}$

A total of 29 urinary symptom-specific measurement tools were identified (Table 3). The majority of questionnaires were developed for female urinary incontinence (and included both symptom indexes as well as incontinencerelated QOL indexes), male voiding symptoms (generally referred to as prostate symptom scores), and a few questionnaires for specific aspects of urinary symptoms, such as nocturia or urinary urgency. The individual questions were 
Table 2 Disease-specific quality of life instruments with items related to neurogenic bladder dysfunction

\begin{tabular}{|c|c|c|}
\hline Population & Instrument & Bladder related questions \\
\hline \multirow[t]{3}{*}{$\mathrm{SCl}$} & Qualiveen & $\begin{array}{l}\text { - } 30 \text { questions about } \\
\text { limitations, constraints, } \\
\text { fears, and feelings related } \\
\text { to bladder function }\end{array}$ \\
\hline & $\begin{array}{l}\text { The Spinal Cord Injury } \\
\text { Secondary Conditions } \\
\text { Scale }\end{array}$ & $\begin{array}{l}\text { Bladder dysfunction: } \\
\text { incontinence, bladder } \\
\text { or kidney stones, kidney } \\
\text { problems, urine leakage, } \\
\text { and urine back up } \\
\text { - Urinary tract infections }\end{array}$ \\
\hline & $\begin{array}{l}\text { Spinal Cord Injury- } \\
\text { Functional Index }\end{array}$ & $\begin{array}{l}\text { - Eleven items related to } \\
\text { ability to carry out bladder } \\
\text { related tasks (catheter } \\
\text { care, genital hygiene) }\end{array}$ \\
\hline \multirow[t]{5}{*}{ MS } & MSQOL-54 & $\begin{array}{l}\text { - Social impact of bladder } \\
\text { function }\end{array}$ \\
\hline & MSIS-29 & $\begin{array}{l}\text { - Bother associated with } \\
\text { urinary urgency }\end{array}$ \\
\hline & $\begin{array}{l}\text { Functional assessment } \\
\text { of MS }\end{array}$ & $\begin{array}{l}\text { - Urinary urgency and } \\
\text { frequency }\end{array}$ \\
\hline & $\begin{array}{l}\text { Hamburg Quality of Life } \\
\text { Questionnaire in MS }\end{array}$ & - Bladder control \\
\hline & MS QOL Inventory & $\begin{array}{l}\text { - Frequency of incontinence, } \\
\text { urgency } \\
\text { - Impact of bladder } \\
\text { of physical activities }\end{array}$ \\
\hline SB & $\begin{array}{l}\text { QOL in SB } \\
\text { Questionnaire }\end{array}$ & - Ability to self-catheterize \\
\hline
\end{tabular}

Abbreviations: MS, multiple sclerosis; MSIS, multiple sclerosis impact scale; MSQOL, multiple sclerosis quality of life; QOL, quality of life; SB, spina bifida; SCl, spinal cord injuries.

extracted, and grouped into categories according to our NBSS dimensions and components (Table 1). A total of 266 questions were identified:

- 90 incontinence questions: differentiate stress, urgency, and unaware incontinence; quantify the severity of incontinence (volume and frequency); assess a patient's ability to control incontinence

- 46 nocturia questions: number of voids during the night, impact on sleep

- 41 urinary urgency questions: frequency and severity of urgency incontinence, specific triggers for urgency

- 32 voiding question: weak stream, straining during voiding, hesitancy, intermittency

- 28 urinary frequency questions: severity, the need for a timetable, longest interval between voiding

- 17 pain/discomfort questions: dysuria, skin irritation, constant suprapubic pain related to the bladder

- ten catheter usage questions

- two infection related questions.
Table 3 Urinary-specific symptom tools and health related quality of life scales (not specific to neurogenic bladder patients)

\begin{tabular}{|c|c|}
\hline Cond & uestions \\
\hline $\begin{array}{l}\text { Female/general } \\
\text { urinary } \\
\text { incontinence }\end{array}$ & $\begin{array}{l}\text { - Incontinence impact questionnaire } \\
\text { - Urge incontinence impact questionnaire } \\
\text { - International consultation on incontinence } \\
\text { questionnaire } \\
\text { - International consultation on incontinence } \\
\text { questionnaire-female lower urinary tract } \\
\text { - symptoms } \\
\text { - Urinary incontinence handicap inventory } \\
\text { - Ininary incontinence severity score } \\
\text { - The prafab-questionnaire score } \\
\text { - Incontinence severity index } \\
\text { - King's health questionnaire } \\
\text { - CONTILIFE } \\
\text { - Incontinence quality of life questionnaire } \\
\text { - Revised urinary incontinence scale } \\
\text { - York incontinence perceptions scale } \\
\text { - International continence society quality of life } \\
\text { - questionnaire } \\
\text { Bladder control self-assessment questionnaire }\end{array}$ \\
\hline $\begin{array}{l}\text { Male urinary } \\
\text { symptoms }\end{array}$ & $\begin{array}{l}\text { - Male urogenital distress inventory } \\
\text { - Male urinary symptom impact questionnaire } \\
\text { - American Urological Association symptom index } \\
\text { - Benign prostatic hyperplasia health related } \\
\text { quality of life survey } \\
\text { - Benign prostatic hyperplasia impact index } \\
\text { - Danish prostatic symptom score-I } \\
\text { - International continence society-male } \\
\text { questionnaire }\end{array}$ \\
\hline $\begin{array}{l}\text { Specific urinary } \\
\text { symptoms }\end{array}$ & $\begin{array}{l}\text { - Nocturia quality of life questionnaire } \\
\text { - Overactive bladder symptom and health related } \\
\text { - } \text { quality of life questionnaire } \\
\text { - Primary questionnaire } \\
\text { - Patient perception of bladder condition } \\
\text { - Intermittent self catheterization questionnaire }\end{array}$ \\
\hline
\end{tabular}

The multidisciplinary group reduced the item pool using a judgment-based approach. Questions that were duplicates, not relevant to neurogenic bladder patients, or not related to specific bladder symptoms or complications were eliminated. The remaining questions were used in the creation of potential items for the NBSS. The items were modified to ensure they were applicable to patients with indwelling catheters, intermittent catheters, and urinary diversions. An adjectival scale was used for the items, with a total of four or five ordinal response options. A single categorical question was included to determine the method of bladder management.

Interviews were conducted with 16 adult patients. This was a diverse group of patients with a variety of ages, impairment levels, device use, and previous urologic surgery; 
demographic details for the SCI and MS patients are presented in Table 4. The interviews suggested that urinary incontinence, urinary tract infections, urgency, and bladder spasms were dominant issues that were relevant to the majority of patients. The dimensions and components outlined in Table 1 adequately covered all relevant concepts identified during the interviews.

A total of 25 questions (14 on symptoms, seven on complications, and four on urinary-related QOL) were included for review by external content experts (Table S1). An electronic survey was sent to 19 experts, of whom 12 responded (63\%; eight urologists, three SCI physiatrists, one neurologist). A total of five questions were eliminated because of perceived redundancy or low importance rating, and five new questions were added based on their feedback (Table 5). No questions were eliminated because of poor answer hierarchy.

During patient pretesting, small changes were made where necessary in the questions and wording to improve interpretation of the items. The Question Understanding Aid ${ }^{12}$ tool identified minor issues, which in most cases were easily corrected. Some issues such as the use of "unfamiliar technical terms" (eg, the words urinary, bladder, or catheter) were unavoidable, and we found they were adequately understood in this population.

\section{Discussion}

PROMs provide a more interpretable and scientifically meaningful measurement than unvalidated patient interviews

Table $4 \mathrm{SCl}$ and $\mathrm{MS}$ patient characteristics for qualitative interview

\begin{tabular}{|c|c|c|}
\hline & SCI & MS \\
\hline Number & 11 & 4 \\
\hline Percent male & $45 \%$ & $50 \%$ \\
\hline Age range (years) & $30-70$ & $44-56$ \\
\hline Lesion level/type & 3 cervical & 2 secondary \\
\hline \multirow[t]{2}{*}{ of MS } & 7 thoracic & progressive, \\
\hline & I lumbar & $\begin{array}{l}2 \text { relapsing/ } \\
\text { remitting }\end{array}$ \\
\hline $\begin{array}{l}\text { Percent that } \\
\text { use intermittent } \\
\text { or indwelling } \\
\text { catheters }\end{array}$ & $81 \%$ & $25 \%$ \\
\hline \multirow{6}{*}{$\begin{array}{l}\text { Previous urologic } \\
\text { surgeries among } \\
\text { these patients }\end{array}$} & Bladder augmentation & Intravesical \\
\hline & Continent catheterizable channel & onabotulinum \\
\hline & Urethral stricture surgery & \\
\hline & Treatment of bladder calculi & \\
\hline & Sphincterotomy & \\
\hline & Ileal conduit urinary diversion & \\
\hline
\end{tabular}

Note: Characteristics of the single SB patient are not shown.

Abbreviations: MS, multiple sclerosis; SCI, spinal cord injuries; SB, spina bifida. or questionnaires, and they allow standardization and comparability between studies; they have become an important endpoint for clinical trials and therapeutic interventions. There is, however, little research and development done on clinical measurement tools for neurogenic bladder patients. Investigators have often been forced to rely on unvalidated or inappropriate instruments to evaluate the neurogenic bladder population. ${ }^{2}$ There are instruments for QOL measurement for specific populations, such as the Quality of Life Profile for Adults with Physical Disabilities ${ }^{16}$ or the Multiple Sclerosis Quality of Life- $54 ;{ }^{3}$ however, these instruments have only a very limited inclusion of items related to neurogenic bladder, making them impractical for many urologic applications. The Qualiveen ${ }^{9}$ was developed to measure urinary-related QOL among SCI patients. While QOL is an important concept, it is not the primary measurement goal of the NBSS. QOL is an abstract concept, usually based on social, functional, and emotional domains. This concept does not allow a clinician or investigator to assess specific clinical domains or relate changes to specific clinical parameters. An intervention may not improve a patient's QOL, however it may significantly change their bladder symptoms. For example, the commonly used American Urology Association Symptom Score ${ }^{17}$ measures male lower urinary tract symptoms. A separate QOL question assesses the impact of those symptoms. These two sections are complementary and do not necessary correlate: severe symptoms can have no impact on a person's QOL, and some patients rate their QOL as poor despite only mild symptoms. The primary goal of the NBSS is to measure neurogenic bladder symptom domains, which is distinct and complementary to urinary related QOL.

The creation of a specific instrument that is designed and validated for symptom assessment among neurogenic bladder patients is a considerable challenge given the spectrum of urinary symptoms and impairments, general mobility restrictions, differing functional abilities, possible catheter usage, and previous urinary reconstructive surgery. For example, many studies have focused on the continence of neurogenic bladder patients. The Incontinence-QOL instrument ${ }^{18}$ was developed to assess female stress and urgency incontinence and was then validated in the neurogenic bladder population. ${ }^{19}$ While the Incontinence-QOL covers issues relevant to general incontinence, it does not address the other important areas of neurogenic bladder dysfunction, such as urinary infection or catheter bypassing. In addition, it includes questions that are not relevant to many neurogenic bladder patients, such as "I have to be careful about standing up after sitting down.” 
Table 5 Results of the external expert review for each domain

\begin{tabular}{|c|c|c|c|c|}
\hline & $\begin{array}{l}\text { Importance rating } \\
\text { (mean, SD) }\end{array}$ & $\begin{array}{l}\text { Agreement with answer } \\
\text { hierarchy (mean, SD) }\end{array}$ & $\begin{array}{l}\text { Action based on } \\
\text { external expert review }\end{array}$ & $\begin{array}{l}\text { Final NBSS for } \\
\text { future testing }\end{array}$ \\
\hline Incontinence questions $(\mathrm{n}=7)$ & $4.0(0.8)$ & $4.0(0.6)$ & 2 questions edited & 7 questions \\
\hline Urgency $(n=2)$ & $3.7(0.6)$ & $4.1(0.6)$ & & 2 questions \\
\hline Nocturia $(n=1)$ & $3.6(0.7)$ & $4.1(0.5)$ & & I question \\
\hline Frequency $(n=1)$ & $4.3(0.6)$ & $4.1(0.3)$ & I new question added & 2 questions \\
\hline Pain $(n=1)$ & $3.1(0.7)$ & $3.5(0.7)$ & & I question \\
\hline Emptying $(n=1)$ & $3.5(0.7)$ & $4.1(0.5)$ & & I question \\
\hline Stream/straining $(n=1)$ & $3.3(1.1)$ & $3.9(0.7)$ & I new question added & 2 questions \\
\hline UTI $(n=2)$ & $3.5(1.0)$ & $4.0(0.6)$ & & 2 questions \\
\hline Stone disease $(n=2)$ & $3.2(0.8)$ & $3.6(0.8)$ & $\begin{array}{l}\text { I question deleted, } \\
\text { I new question added }\end{array}$ & 2 questions \\
\hline Renal failure $(\mathrm{n}=\mathrm{I})$ & $3.75(0.8)$ & $3.7(0.8)$ & I question deleted & 0 questions \\
\hline Catheter usage $(n=1)$ & $3.9(0.8)$ & $3.8(0.6)$ & & I question \\
\hline Medication usage $(n=I)$ & $3.9(0.9)$ & $4.3(0.5)$ & I new question added & 2 questions \\
\hline $\mathrm{QOL}(\mathrm{n}=4)$ & $4.0(0.9)$ & $4.1(0.6)$ & $\begin{array}{l}3 \text { questions deleted, } \\
\text { I new question added }\end{array}$ & 2 questions \\
\hline
\end{tabular}

Notes: Question importance was ranked on a scale of I (not important) to 5 (very important). Agreement with the hierarchy of the answers was ranked on a scale of I (no hierarchy) to 5 (good hierarchy).

Abbreviations: NBSS, neurogenic bladder symptom score; QOL, quality of life; SD, standard deviation; UTI, urinary tract infection.

SCI, MS, and SB patients are a diverse group, that are often assembled into a single cohort for studies of urologic interventions, such as oral anticholinergic therapy, intravesical onabotulinum toxin, bladder augmentation, or urinary diversion. ${ }^{1}$ The NBSS will assess these interventions with a single PROM that could be used for patients with catheters, urinary diversions, or spontaneous voiding. Moreover, by focusing on symptoms, the domains are easy to conceptualize and understand and may be used to measure specific clinical changes in a simple and efficient manner. The proposed domain structure of the NBSS will also allow clinicians to look at specific subscales, for example urinary incontinence, if that is their primary interest. In addition, domains which are frequently not measured in PROMs, such as stone disease and medication side effects, are included.

The strengths of the development process so far include a multidisciplinary approach to generating potential items for the NBSS. We believe the steps we have taken thus far, and the external expert review, demonstrate an acceptable face validity for the NBSS. Items have been designed to be potentially responsive to interventions aimed at treating symptoms or consequences of neurogenic bladder dysfunction. Potential limitations of our development process include a single language (English) and cultural setting (Canada), which may limit future international generalizability. While we strove to maximize generalizability, some domains could not be included. For example, renal failure and autonomic dysreflexia are two topics we felt we could not adequately address using a PROM given the complexity and specific medical facts that would be necessary to meaningfully assess these area. Further study is currently underway to examine the domain structure (Table 1), with factor analysis, and to establish the construct validity and reliability of the NBSS.

\section{Conclusion}

This paper summarizes the initial steps in the development of a NBSS. Using the available literature, patient interviews, and expert opinion, a 25-item questionnaire has been created to assess bladder symptoms and consequences among neurogenic bladder patients. The methods undertaken thus far, and the results of the external review by content experts, demonstrate the face and content validity of the NBSS. Additional study is underway to assess the measurement properties of the NBSS.

\section{Acknowledgment}

This investigator-driven research was supported by the CUA Astellas Research Grant Program funded by Astellas Pharma Canada, Inc., and jointly established by Astellas Pharma Canada, Inc., and the Canadian Urological Association. All authors contributed substantially to this work. BW is the primary author and was responsible for study design and data analysis. BW, SAM, PP, and KS made up the expert committee and were responsible for item generation and review as well as manuscript content. WM was responsible for patient interviews, data collection, and the literature review. 


\section{Disclosure}

BW has received speaker fees from Astellas, Pfizer, and Allergan. SAM, PP, KS and WM report no conflicts of interest in this work.

\section{References}

1. Stöhrer M, Blok B, Castro-Diaz D, et al. EAU guidelines on neurogenic lower urinary tract dysfunction. Eur Urol. 2009;56(1):81-88.

2. $\mathrm{Ku} \mathrm{JH}$. The management of neurogenic bladder and quality of life in spinal cord injury. BJU Int. 2006;98(4):739-745.

3. Vickrey BG, Hays RD, Harooni R, Myers LW, Ellison GW. A healthrelated quality of life measure for multiple sclerosis. Qual Life Res. 1995;4(3):187-206.

4. Sawin KJ, Bellin MH. Quality of life in individuals with spina bifida: a research update. Dev Disabil Res Rev. 2010;16(1):47-59.

5. Jeong SJ, Cho SY, Oh SJ. Spinal cord/brain injury and the neurogenic bladder. Urol Clin North Am. 2010;37(4):537-546.

6. Kalsi V, Fowler CJ. Therapy insight: bladder dysfunction associated with multiple sclerosis. Nat Clin Pract Urol. 2005;2(10):492-501.

7. Stoffel JT. Contemporary management of the neurogenic bladder for multiple sclerosis patients. Urol Clin North Am. 2010;37(4):547-557.

8. Patki PS, Hamid R, Arumugam K, Shah PJ, Craggs M. Botulinum toxin-type $\mathrm{A}$ in the treatment of drug-resistant neurogenic detrusor overactivity secondary to traumatic spinal cord injury. BJU Int. 2006;98(1): 77-82.

9. Costa P, Perrouin-Verbe B, Colvez A, et al. Quality of life in spinal cord injury patients with urinary difficulties. Development and validation of qualiveen. Eur Urol. 2001;39(1):107-113.

10. Streiner DL, Norman GR. Health Measurment Scales: A Practical Guide to Their Development and Use. 4th ed. New York, NY: Oxford University Press; 2008.
11. Lynn MR. Determination and quantification of content validity. Nurs Res. 1986;35(6):382-385.

12. Graesser AC, Wiemer-Hastings K, Kreuz R, Wiemer-Hastings P, Marquis K. QUAID: a questionnaire evaluation aid for survey methodologists. Behav Res Methods Instrum Comput. 2000;32(2): 254-262.

13. Tulsky DS, Kisala PA, Victorson D, et al. Developing a contemporary patient-reported outcomes measure for spinal cord injury. Arch Phys Med Rehabil. 2011;92(Suppl 10):S44-S51.

14. Kalpakjian CZ, Scelza WM, Forchheimer MB, Toussaint LL. Preliminary reliability and validity of a Spinal Cord Injury Secondary Conditions Scale. J Spinal Cord Med. 2007;30(2):131-139.

15. Biering-Sørensen F, Craggs M, Kennelly M, Schick E, Wyndaele JJ. International lower urinary tract function basic spinal cord injury data set. Spinal Cord. 2008;46(5):325-330.

16. Renwick R, Nourhaghighi N, Manns PJ, Rudman DL. Quality of life for people with physical disabilities: a new instrument. Int J Rehabil Res. 2003;26(4):279-287.

17. Barry MJ, Fowler FJ Jr, O’Leary MP, et al. The American Urological Association symptom index for benign prostatic hyperplasia. The Measurement Committee of the American Urological Association. J Urol. 1992;148(5):1549-1557; discussion 1564.

18. Patrick DL, Martin ML, Bushnell DM, Yalcin I, Wagner TH, Buesching DP. Quality of life of women with urinary incontinence: further development of the incontinence quality of life instrument (I-QOL). Urology. 1999;53(1):71-76.

19. Schurch B, Denys P, Kozma CM, Reese PR, Slaton T, Barron R. Reliability and validity of the Incontinence Quality of Life questionnaire in patients with neurogenic urinary incontinence. Arch Phys Med Rehabil. 2007;88(5):646-652. 


\section{Supplementary materials}

Table SI Proposed items for the neurogenic bladder symptom score

I. I usually manage my bladder or urine function:

- With a catheter in all the time, or a urostomy bag

- With a condom catheter

- With an intermittent catheter

- By just urinating in the toilet

2. During the day, how often do you have urine leakage (including leakage around a catheter or stoma):

- More than once a day

- About once a day

- A few times a week

- Rarely

- Zero - don't have urine leakage

3. During the day, the amount of urine leakage (including leakage around a catheter or stoma):

- Requires 3 or more pads

- Requires 2 pads

- Requires I pad

- Is minimal and doesn't require pads

- Is zero - I don't have urine leakage

4. During the day, the amount of urine leakage (including leakage around a catheter or stoma) is:

- Large (clothes/pads are soaked)

- Medium (clothes/pads are wet)

- Small (clothes/pads are damp)

- Minimal

- Zero - I don't have urine leakage

5. When I am asleep, the amount of urine leakage (including leakage around a catheter or stoma) is:

- Large (it makes things soaked)

- Medium (it makes things wet)

- Small (it makes things damp)

- Minimal

- Zero - I don't have urine leakage

6. Urine leakage has changed the amount of liquid I drink

- Agree - I reduce my liquid intake all the time

- Agree - I reduce my liquid intake some of the time

- Disagree - Leakage hasn't caused me to change my liquid intake

- Disagree - I don't have any urine leakage

7. Urine leakage has caused skin problems.

- Agree - I see a doctor for the skin problems

- Agree - I am able to manage the skin problems myself

- Disagree - Leakage doesn't cause any skin problems

- Disagree - I don't have any urine leakage

8. Urine leakage limits the activities I enjoy.

- Agree - It limits all my activities

- Agree - It limits some of my activities

- Disagree - It doesn't limit any of my activities

- Disagree - I don't have any urinary leakage

9. The sudden urge to urinate, (or bladder spasm) occurs:

- Many times a day

- A few times a day

- Rarely

- Never

(Continued)

\section{Table SI (Continued)}

10. When I need to urinate or use an intermittent catheter:

- I have to do this right away or I may leak urine

- I can only delay this a few minutes or I may leak urine

- I can do this when it is convenient without leaking urine

- I don't think about urinating. I have a catheter or stoma bag

II. During my nighttime sleep, I need to urinate, use a catheter, or fix my catheter or stoma bag:

- Three or more times

- Twice

- Once

- Rarely

- Never

12. During the day, the longest I can go between urinating, using a catheter, or emptying my urine bag is:

- Less than an hour

- About I-2 hours

- About 2-3 hours

- More than 3 hours

13. During the day, the longest time I can stay dry without any urine leakage is:

- Less than an hour

- About I-2 hours

- About 2-3 hours

- More than 3 hours

- This isn't an issue for me. I don't have urine leakage

14. Urinating or using urinary catheters cause me pain or discomfort:

- Most of the time

- Sometimes

- Rarely

- Never

15. When I am done urinating or using a catheter, my bladder or urinary reservoir still feels full.

- Agree - This happens most of the time

- Agree - This happens some of the time

- Disagree - This doesn't happen after I urinate

- This isn't an issue for me. I don't feel my bladder, or I use a catheter or stoma bag

16. When I urinate my urinary stream:

- Drips out

- Comes out with a weak stream

- Comes out with a strong stream

- This isn't an issue for me. I use a catheter or stoma bag

17. When I urinate I have to strain or push to empty my bladder or urinary reservoir.

- Agree - This happens most of the time

- Agree - This happens some of the time

- Disagree - I don't do this when I urinate

- This isn't an issue for me. I use a catheter or stoma bag

18. I have a urinary tract infection with symptoms (for example pain, foul smelling urine, fever):

- Once a month, or more

- Once every few months

- A few times a year

- About once a year or less

- Never

(Continued) 
Table SI (Continued)

19. For me, urinary tract infections:

- Often require me to be admitted to hospital

- Require me to take antibiotics all the time

- Can be treated at home with antibiotics when necessary

- Can be treated without antibiotics

- Do not occur

20. I have kidney stones:

- More than once a year

- Less than once a year

- A long time ago

- Never

21. I have had bladder stones:

- More than once a year

- Less than once a year

- A long time ago

- Never

22. I need to take pills or medications for my urination or bladder.

- Agree - However I don't take them

- Agree - They cause significant side effects for me

- Agree - They cause minimal or no side effects for me

- Disagree - No pills or medications are needed for my bladder

23. I find the pills or medications I use for my urination or bladder are:

- Effective

- Partially effective

- Not very effective

- I don't take pills or medications for my bladder

24. If you had to live the rest of your life with the way your bladder or urinary reservoir currently works, how would you feel?

- Unhappy

- Mostly unsatisfied

- Mixed: equally satisfied and unsatisfied

- Mostly satisfied

- Pleased

25. All things considered, how satisfied are you with the way your bladder or urinary reservoir currently works?

- Very unsatisfied

- Mostly unsatisfied

- Mixed: equally satisfied and unsatisfied

- Mostly satisfied

- Very satisfied

Research and Reports in Urology

\section{Publish your work in this journal}

Research and Reports in Urology is an international, peer-reviewed, open access journal publishing original research, reports, editorials, reviews and commentaries on all aspects of adult and pediatric urology in the clinic and laboratory including the following topics: Pathology, pathophysiology of urological disease; Investigation and treatment of

urological disease; Pharmacology of drugs used for the treatment of urological disease. The manuscript management system is completely online and includes a very quick and fair peer-review system, which is all easy to use. Visit http://www.dovepress.com/testimonials.php to read real quotes from published authors. 